\title{
Analysis of Concrete Containing Different Admixtures as Partial Replacement of Cement
}

\author{
Rahul Chaudhary, Shahbaz Ahamad, Nabiullah Khan and Varshney Kumar \\ Patel \\ Department of Civil Engineering, Suyash Institute of Information Technology Gorakhpur, Uttar Pradesh, India
}

\begin{abstract}
Concrete is the most extensively used man-made construction material in the world. Its most important quality is its versatility and the ability to design the concrete of any required properties according to the environment. . Human development in today's scenario is impossible without the excessive use of concrete. Cement is the most important component of concrete. Unfortunately production of cement emits a very large amount of greenhouse gases and possess a very potential threat to the atmosphere. Thus it is inevitable for the sustainable development of human life that the dependency on cement to obtain strength in concrete should be lowered. This is the main reason to obtain a suitable replacement of cement to obtain high strength concrete at a low cost incurred. Also the modern constructions require very high strength in concrete which is only possible by mixing a suitable quantity of admixtures in the concrete. Silica fume, Rice Husk Ash and Iron Slag are abundantly available industrial waste products in India. Due to the latest imposed rules and regulations their disposal has become costly. Thus it is necessary to find a suitable useful way to utilize these waste materials. These materials have high siliceous content and pozzolanic properties thus these can be used as a replacement of cement in concrete mix and may also be used as admixture to obtain high strength. Flexural and compressive strengths are the two most important criteria that determine the performance of concrete in any field usage. Thus it is pertinent to obtain the effect of these admixtures on the flexural and compressive strength of concrete. A comparative study can analyze the relative effect of these admixtures on the strength of concrete so that the most suitable admixture can be utilized according to any existing situation.
\end{abstract}

Keywords: Replacement of Cement, admixtures of concrete, flexural strength, compressive Strength

\section{INTRODUCTION}

Concrete is these days the most broadly utilized man-made construction material on the planet. It is gotten by blending cementitious materials, water, aggregate and infrequently admixtures in required extents. Green concrete or plastic concrete is naturally blended material which can be formed into any shape and after solidifying changes over into a stone like mass known as concrete. The solidifying is a result of the concoction response amongst the water and cement, which proceeds for long period prompting stronger concrete with age. The Ordinary Portland Cement (OPC) is one of the main ingredients used for the production of concrete and has no alternative in the civil construction industry.

Tragically, creation of concrete includes discharge of a lot of carbon-dioxide gas into the environment, a noteworthy donor for green house impact and the worldwide temperature alteration, henceforth it is inescapable either to scan for other material as a substitution of bond or incompletely supplant it by some other material. The scan for any such material, which can be utilized as an option or as a supplement for cement should prompt worldwide manageable improvement and most minimal conceivable ecological effect.

Flexural strength and compressive strength of concrete are two most important properties for the design purposes. These properties directly signify the load bearing capacity of the beam specimen when it is used in field operations. But these properties are greatly affected by the composition of the concrete mix design and also due to the presence of some external materials and other environmental factors. Thus it is very beneficial to analyse the effect of various mineral admixtures on compressive strength and flexural strength when they are used as a partial replacement of cement in concrete mix design so that the response of the hardened concrete mix to external applied load can be evaluated. Also mineral admixtures are generally industrial waste materials that are very abundantly available in India. Their disposal is a big challenge and if disposed carelessly then these have a deleterious effect both on the land and the environment. Also the manufacture of cement in the factories is a major source of emission of greenhouse gases in the atmosphere that are the major causes of global warming. Due to the latest rules and regulations about the disposal and emission of wastes it is necessary to find an alternate way to efficiently dispose or use the 
industrial waste product and it is a major concern for a sustainable development of human life. Also when used in correct proportions some mineral admixtures can impart very high strength to the concrete and are thus used in the production of High Performance Concrete (HPC). Three admixtures namely Silica Fume, Rice Husk Ash and Iron Slag are used in this project work as partial replacement of cement in the concrete mix. All these materials are industrial waste products and can be easily obtained in India. Silica Fume is a waste product of silicon industry, Rice Husk Ash and Iron Slag are the waste products from the rice husk boilers and the iron manufacturing industry respectively. All these materials have high siliceous content and pozzolanic properties and due to this can be suitably used to replace cement partially from concrete mix without affecting the strength of hardened concrete due to their high pozzolanic properties.

\section{MATERIALS USED}

An easy way to comply with the conference paper formatting requirements is to use this document as a template and simply type your text into it.

The materials that are used in this study are:

i. Cement

ii. Sand (Fine aggregate)

iii. Coarse aggregate

iv. Silica fume

v. Rice Husk Ash (RHA)

vi. Iron slag

vii. Water

viii. Super plasticizer

\subsection{Cement}

ACC cement of OPC 43 grade confirming to the IS: 8112-1989 is used for the preparation of concrete mix.

\subsection{Fine Aggregate}

Yellow sand that is commercially available in the market was used as fine aggregate in the preparation of concrete mix. The sand belong to the Grade II according to the specifications of IS: 10262-2009.

\subsection{Coarse Aggregates}

Crushed angular coarse aggregates of nominal size $20 \mathrm{~mm}$ and $10 \mathrm{~mm}$ were used in the ratio of 60:40.the crushed rock angular aggregates commercially available were used and the concrete mix design was based on the proportion of the $10 \mathrm{~mm}$ and $20 \mathrm{~mm}$ aggregates.

\subsection{Silica Fume}

Silica rage is a by-result of the make of silicon metal and ferro-silicon amalgams. The procedure includes the diminishment of high virtue quartz ( $\mathrm{SiO} 2)$ in electric circular segment heaters at temperatures in overabundance of $2,000^{\circ} \mathrm{C}$. Silica rage is a fine powder comprising principally of round particles or microspheres of mean diameter around 0.15 microns, with a high particular surface region (15,000-25,000 $\mathrm{m} 2 / \mathrm{kg}$ ). Each microsphere is by and large 100 times littler than a normal bond grain. For this venture the silica rage was gotten that is economically accessible in the Delhi advertise (fig.3.4). It is white in shading and is as fine white powder.

\subsection{Rice Husk Ash (RHA)}

Rice husk is an agricultural waste product obtained from the rice crop. This rice husk is used for steam generation in Rice Husk Boilers and thereby giving a black ash as waste product. This black ash is called the Rice Husk Ash and is a very rich source of silica and has high pozzolanic properties. For the purpose of this project rice husk ash was obtained from Sardar Nagar Distillery, Gorakhpur.

\subsection{Iron Slag}

Iron slag is a waste product of the iron manufacturing and purifying process. During the iron manufacturing process the blast furnace is charged with iron ore and coke and fluxes are added to the ore in the furnace. The iron is mainly oxidized in the form of iron oxide and the impurities are remained as waste product called Iron Slag. This slag is then dried up and grinded to obtain the iron slag in powdered form. For the purpose of this project Iron Slag was obtained from Gallantt Industries, Gorakhpur

\section{PROCEDURE}

Concrete mix of grade M30 confirming to IS: 10262-2009 was designed for the preparation of test samples. The proportion of various components of the concrete mix are given in table- 1 .

Table-1. Concrete Mix Design

\begin{tabular}{|l|l|}
\hline Type of component of mix & Weight per $\mathrm{m} 3(\mathrm{~kg})$ \\
\hline Cement & 354 \\
\hline Fine aggregate & 815 \\
\hline Coarse aggregate & 1217 \\
\hline Water & 152 \\
\hline Super plasticizer & $1 \%$ by weight of cement \\
\hline
\end{tabular}

The ratio of cement: fine aggregate: coarse aggregate

Water/ cement ratio is taken as 0.43 is calculated as $1: 2.3: 3.43$ 
Then the cement was replaced in different proportion by different mineral admixtures by mass using one admixture at a time. Cement was replaced by $5 \%, 10 \%, 15 \%$ and $20 \%$ by mass and test samples of prismatic beams and cubes were casted for different proportions of cement and mineral admixtures to calculate the flexural and compressive strength respectively. The various types of mixes prepared and their proportions are given in Table-2. Here Mix 0 is for the concrete mix without any admixture used and Mix 1, Mix 2, Mix 3 and Mix 4 denotes the concrete mix proportions containing $5 \%$, $10 \%, 15 \%$ and $20 \%$ admixtures as partial replacement of cement.

Tabl-2. Different Concrete Mix Proportions Used

\begin{tabular}{|c|c|c|c|c|c|c|}
\hline $\begin{array}{c}\text { Type of Mix } \\
\text { Proportions }\end{array}$ & $\begin{array}{c}\text { Quantity of } \\
\text { cement } \\
(\mathrm{kg} / \mathrm{m} 3)\end{array}$ & $\begin{array}{c}\text { Quantity of } \\
\text { Admixture } \\
(\mathrm{kg} / \mathrm{m} 3)\end{array}$ & $\begin{array}{c}\text { Coarse } \\
\text { aggregate }\end{array}$ & $\begin{array}{c}\text { Type of Mix } \\
\text { Proportions }\end{array}$ & $\begin{array}{c}\text { Quantity of } \\
\text { cement } \\
(\mathrm{kg} / \mathrm{m} 3)\end{array}$ & $\begin{array}{c}\text { Quantity of } \\
\text { Admixture } \\
(\mathrm{kg} / \mathrm{m} 3)\end{array}$ \\
\hline Mix 0 & 354 & 0 & 1216 & 815 & 148 & 3.54 \\
\hline Mix 1 & 336.3 & 17.7 & 1216 & 815 & 148 & 3.54 \\
\hline Mix 2 & 318.6 & 35.4 & 1216 & 815 & 148 & 3.54 \\
\hline Mix 3 & 300.9 & 53.1 & 1216 & 815 & 148 & 3.54 \\
\hline Mix 4 & 283.2 & 70.8 & 1216 & 815 & 148 & 3.54 \\
\hline
\end{tabular}

\subsection{Test Samples}

Total 39 Beams and 24 Cubes were casted for different proportions of cement and mineral admixtures. The replacement of cement was given in the proportion of 5\%,10\%, $15 \%$ and $20 \%$ using one admixture at a time. The prismatic beams were tested on 7, 14 and 28 days after curing in fresh water. The cubes were tested on 7 and 28 days after preparation. The results were obtained for flexural strength and compressive strength according to the guidelines of IS :516-1959 and the results were obtained for replacement of cement with different mineral admixtures. The results were shown in graphical form and then comparative analysis graphs showing the effect of various mineral admixtures on the flexural and compressive strength of concrete were drawn for 7,14 and 28 days.

3.1.1 Prismatic beams- 39 beams of dimension $700 * 150 * 150 \mathrm{~mm}$ were casted 12 beams were casted on each percentage of replacement of cement with 3 different mineral admixtures using one at a time..The cement was replaced by mass in the percentage of $5 \%$, $10 \%, 15 \%$ and $20 \%$.The beams were tested for the flexural strength of concrete on 7,14 and 28 days after curing in fresh water.

3.1.2Concrete Cubes- 24 concrete cubes of dimension $150 * 150 * 150 \mathrm{~mm}$ were casted for different replacement of cement by mineral admixtures. The concrete cubes were tested on 7 and 28 days to calculate the compressive strength of concrete.

\subsection{Experimental Setup for Flexural Strength Test}

Flexural strength of beams was tested according to the guidelines of IS: 516-1959 and by using a manual flexural strength testing machine.

The beams were placed on the roller support on flexural load testing machine and load was applied gradually at the top face of the beam as it was casted in the mould manually. The reading of the load $(\mathrm{P})$ at which the beam fails is noted down from the dial and then the modulus of rupture or flexural strength was calculated by the formula

The modulus of rupture is calculated as follows:

$$
\mathrm{R}=\mathrm{Pl} /(\mathrm{bd} 2)
$$

Where:

$\mathrm{R}=$ Modulus of rupture or flexural strength in $\mathrm{MPa}$

$\mathrm{P}=$ Maximum applied load indicated by the testing

machine in $\mathrm{N}$

$1=$ Span length in $\mathrm{mm}$

$\mathrm{b}=$ Average width of specimen in $\mathrm{mm}$

$\mathrm{d}=$ Average depth of specimen in $\mathrm{mm}$

\subsection{Experimental Setup for Compressive Strength} Test:-

The compressive strength of concrete cubes were tested by using automatic compressive strength testing machine (Fig.3.13) by applying the load at the side faces of cube as they were cast in the mould. The load was applied gradually and the compressive load was noted down from the dial. Then the compressive strength was calculated by Compressive strength= compressive load $\mathrm{P}$ (Newton)/ ( $\mathrm{b}^{*} \mathrm{~d}$ )

The results of the flexural strength and compressive strength were calculated for different mineral admixtures and then the effect of different admixtures on strength of concrete were shown with the help of graphs and tables.

\section{RESULTS}

In this project work cement was replaced with Mineral admixture by 5\%,10\%, 15\% and $20 \%$. Beams and cubes were casted for each replacement of cement. The concrete beams were tested after 7 , 14 , and 28 days from preparation and the cubes were tested after 7 and 28 days. The cement was replaced in concrete mix by mass while keeping all the other components constant. The beams and cubes were kept in fresh curing water at temperature $27+20 \mathrm{C}$ after the removal from mould and were tested in wet 
condition after taking them out from the water. The beams were tested by Third Point Loading Method according to IS: 516-1959. The results obtained for the flexural strength of concrete containing silica fume as partial replacement of cement is given by Table 3.

Tabl-3. Different Concrete Mix Proportions Used

\begin{tabular}{|c|c|c|c|c|c|c|c|c|c|c|}
\hline \multirow{3}{*}{$\begin{array}{l}\text { Sl. } \\
\text { No } \\
\text {. }\end{array}$} & \multirow{3}{*}{$\begin{array}{c}\text { \% replacement } \\
\text { of cement by } \\
\text { Mineral } \\
\text { admixture }\end{array}$} & \multicolumn{9}{|c|}{ FLEXURAL STRENGTH (M Pa) } \\
\hline & & \multicolumn{3}{|c|}{7 Days } & \multicolumn{3}{|c|}{14 Days } & \multicolumn{3}{|c|}{28 Days } \\
\hline & & $\begin{array}{l}\text { Silica } \\
\text { fume }\end{array}$ & RHA & $\begin{array}{l}\text { Iron } \\
\text { Slag }\end{array}$ & $\begin{array}{l}\text { Silica } \\
\text { fume }\end{array}$ & RHA & $\begin{array}{l}\text { Iron } \\
\text { Slag }\end{array}$ & $\begin{array}{l}\text { Silica } \\
\text { fume }\end{array}$ & RHA & $\begin{array}{l}\text { Iron } \\
\text { Slag }\end{array}$ \\
\hline 1 & 0 & 3.56 & 3.56 & 3.56 & 4 & 4 & 4 & 4.3 & 4.3 & 4.3 \\
\hline 2 & 5 & 3.56 & 4 & 2.96 & 3.71 & 4.15 & 3.4 & 5.04 & 5 & 4.3 \\
\hline 3 & 10 & 3.71 & 3.4 & 3.4 & 4.2 & 4 & 3.48 & 5.34 & 4.36 & 5.19 \\
\hline 4 & 15 & 3.86 & 2.67 & 4.082 & 4.3 & 3.67 & 4.12 & 5.63 & 4.0 & 5.24 \\
\hline 5 & 20 & 3.4 & 2.22 & 3.48 & 3.44 & 3.44 & 3.52 & 4.6 & 3.74 & 4.22 \\
\hline
\end{tabular}

4.1 Comparison of 7 Days Flexural Strength of Concrete The comparison of flexural strength is done by the plotting a collective graph on the same scale showing the variation of flexural strength of concrete with different admixtures used as a partial replacement of cement .The variation of flexural strength at 7 days after preparation of samples are given by Fig-1.

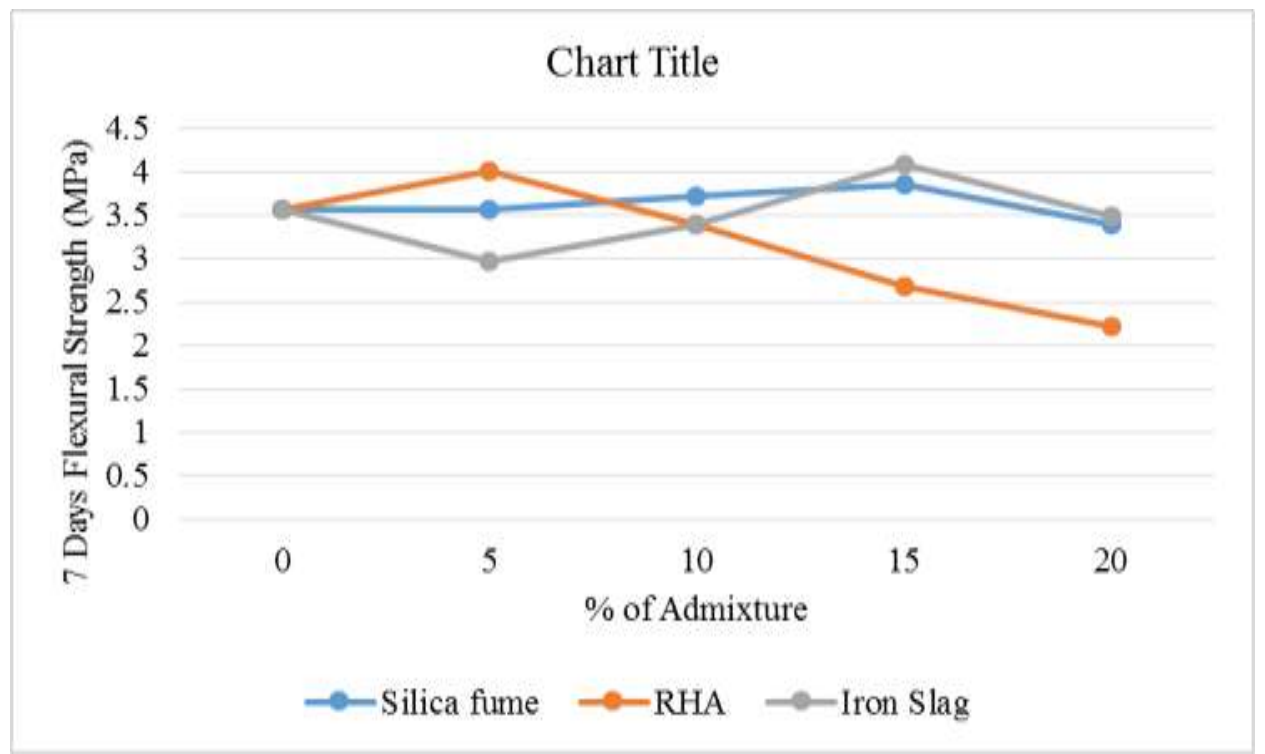

Fig-1. Flexural Strength Test Result after 7 Days

It can be seen here that silica fume and iron slag gives a comparatively high value of flexural strength at 7 days in comparison to RHA. Silica fume gives the maximum value at $15 \%$ replacement of cement and iron slag also gives the highest value of flexural strength at $15 \%$ replacement of cement after which the value decreases. The RHA gives the lowest value for the flexural strength. The value obtained with RHA was also lower than the value of flexural strength of concrete when no replacement of cement was done.

\subsection{Comparison of 14 Days Flexural Strength}

14 day flexural strength test results are shown in a comparative way in the Fig-2. It can be seen from the graph that the flexural strength of concrete with silica fume shown a increase in strength as compared to 7 day results. But the values of flexural strength for RHA and iron slag as replacement were not much improved. The value of flexural strength goes on decreasing as the percentage of RHA is increase in the concrete. The value for replacement with iron slag has shown only a little increase in flexural strength. 


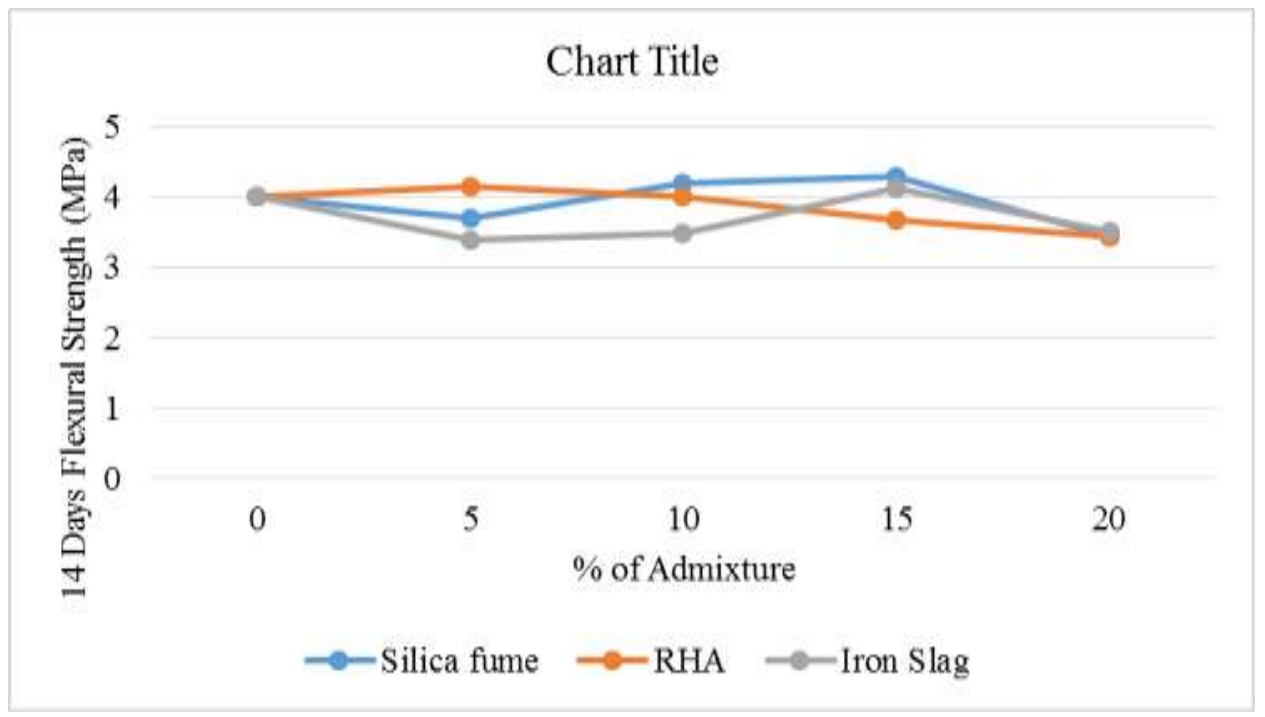

Fig-2. Flexural Strength Test Result after 14 Days

4.3 Comparative Study on 28 Days Flexural StrengthThe comparative variation of flexural strength for different mineral admixtures after 28 days is given by the Fig-3.

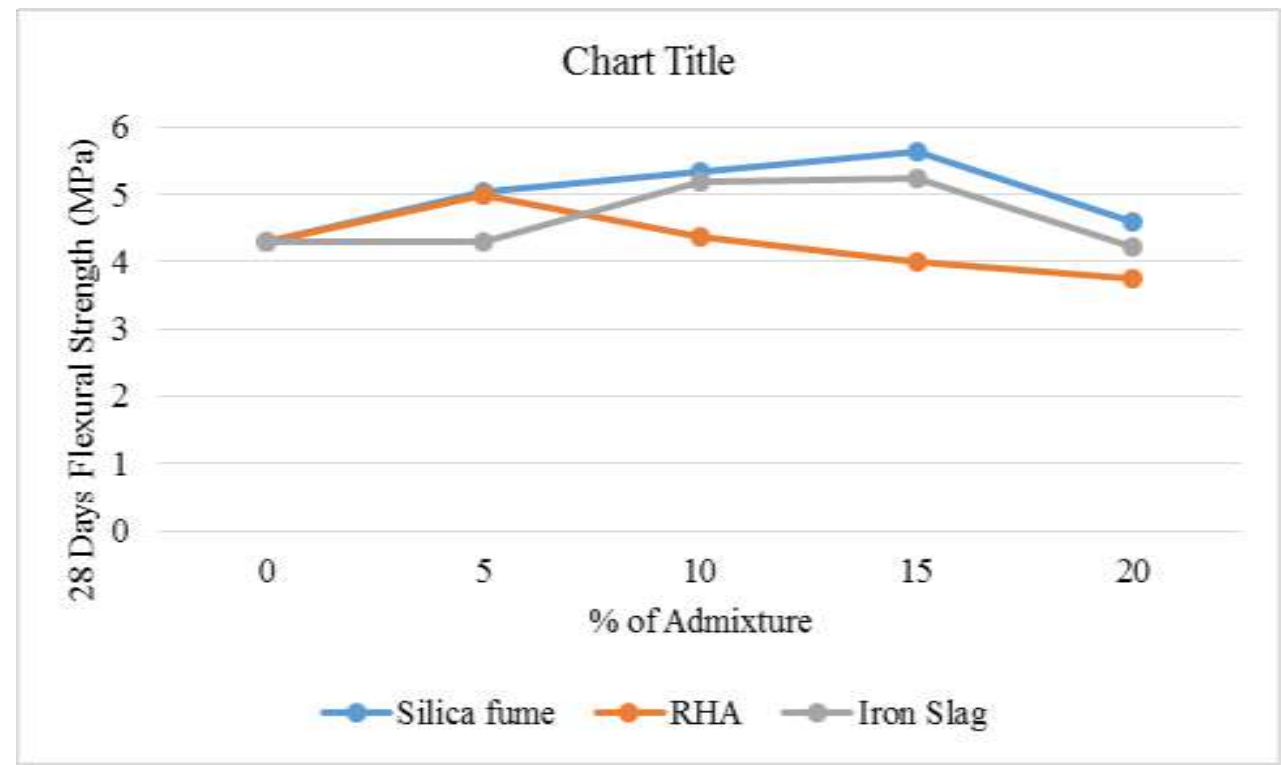

Fig-3. Flexural Strength Test Result after 28 Days

It can be noted that the value of flexural strength for replacement of cement with silica fume is much higher in comparison to the strength obtained by iron slag and RHA. Of all the three mineral admixtures used RHA gave the lowest values in all the three tests. Thus silica fume is the most suitable mineral admixture to replace cement to obtain High Performance Concrete.

4.5 Comparative Study of Effect of Different Admixtures as Partial Replacement of Cement on Compressive Strength
To obtain a comparative effect of different admixtures on the compressive strength of concrete the values obtained for different proportional replacement of cement with the admixtures were shown in a collective manner in table 4 and the comparative variation was shown by drawing graphs on a common scale for all the three different admixtures. 

ISSN : 2248-9622, Vol. 7, Issue 6, ( Part-6) June 2017, pp.00-00

Table-4. Compressive Strength of Concrete

\begin{tabular}{|c|c|c|c|c|c|c|c|}
\hline \multirow{3}{*}{$\begin{array}{l}\text { Sr. } \\
\text { No }\end{array}$} & \multirow{3}{*}{$\begin{array}{c}\% \text { of mineral } \\
\text { admixture as } \\
\text { replacement of } \\
\text { cement }\end{array}$} & \multicolumn{6}{|c|}{ Compressive Strength(M Pa) } \\
\hline & & \multicolumn{3}{|c|}{7 days compressive strength } & \multicolumn{3}{|c|}{28 days compressive strength } \\
\hline & & $\begin{array}{l}\text { Silica } \\
\text { Fume }\end{array}$ & RHA & Iron slag & $\begin{array}{l}\text { Silica } \\
\text { fume }\end{array}$ & RHA & $\begin{array}{l}\text { Iron } \\
\text { slag }\end{array}$ \\
\hline 1 & 0 & 23.6 & 23.6 & 23.6 & 38.2 & 38.2 & 38.2 \\
\hline 2 & 5 & 24.5 & 22.3 & 26.3 & 40.2 & 32 & 31.2 \\
\hline 3 & 10 & 27.2 & 21.4 & 23.6 & 41.1 & 31 & 35 \\
\hline 4 & 15 & 27.6 & 17.4 & 22.3 & 42 & 29.1 & 37 \\
\hline 5 & 20 & 22.2 & 16 & 21.4 & 37.4 & 27.5 & 30 \\
\hline
\end{tabular}

The comparative variation of compressive strength with partial replacement of cement with different mineral admixtures is given in Fig-4. and Fig-5.

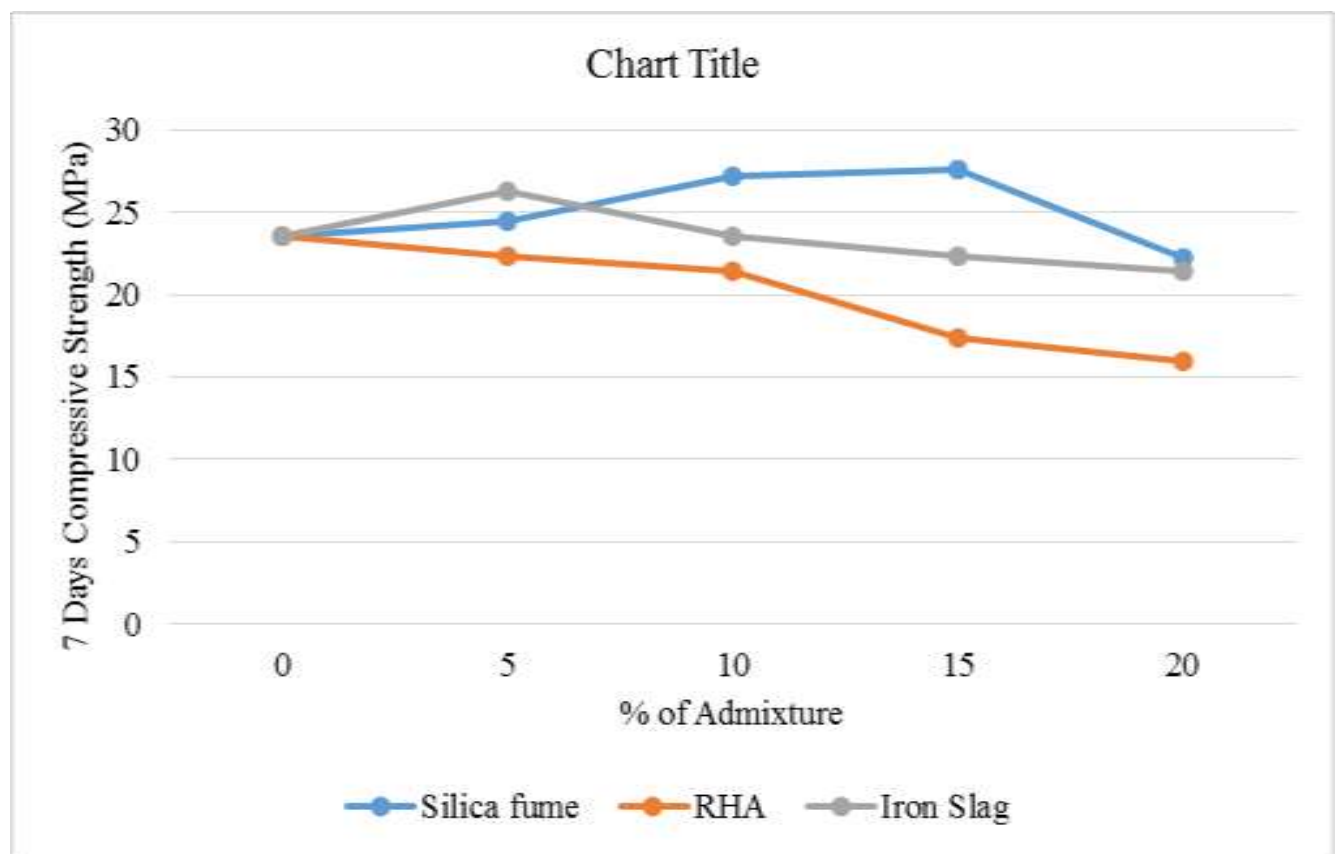

Fig-4. Compressive Strength test result after 28 Days

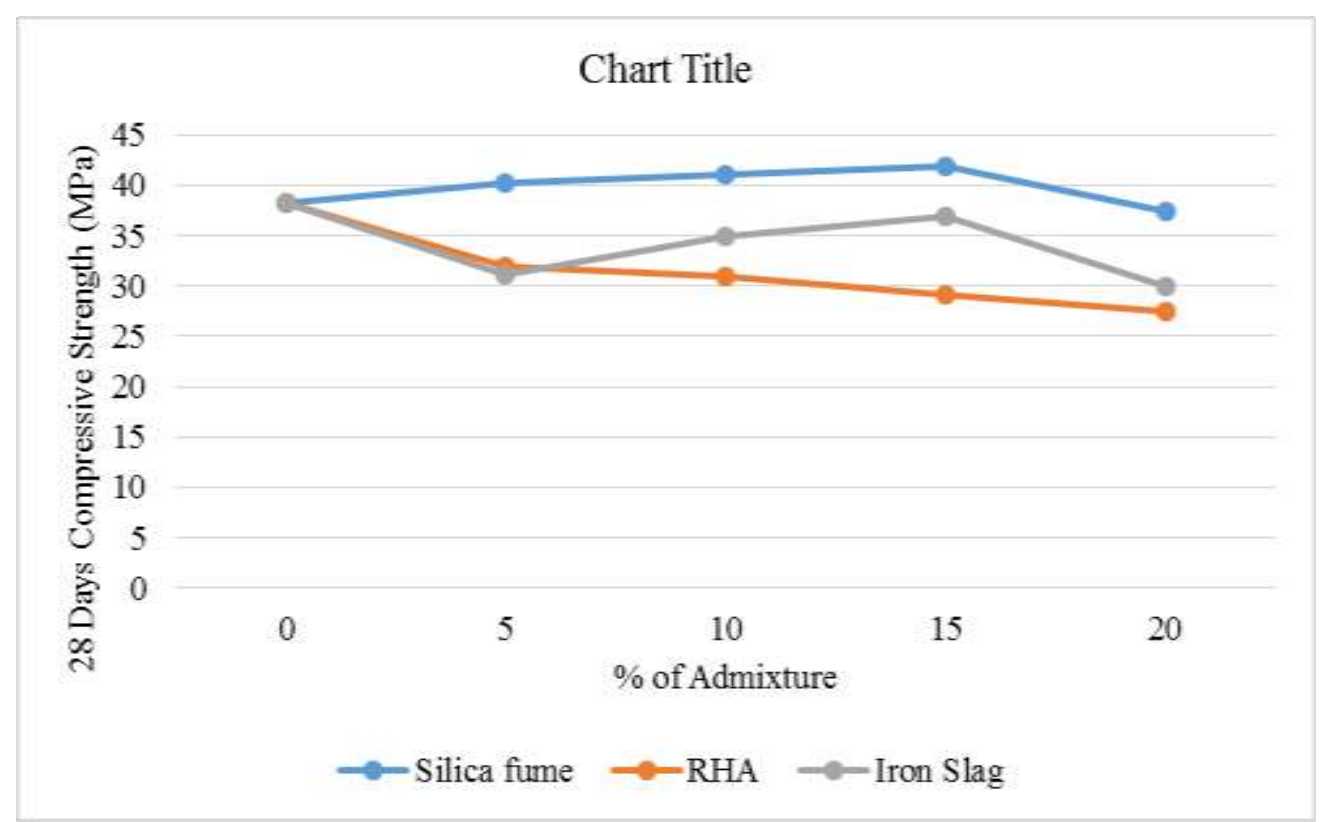

Fig-5. Compressive Strength test result after 28 Days 
It can be seen from the Figures above that silica fume gives the highest values of compressive strength followed by iron slag and RHA gives the lowest value of compressive strength which is much lower than the compressive strength of concrete without any replacement of cement.

\section{CONCLUSIONS}

In this research work Flexural and compressive strength tests were conducted on concrete beams and cubes samples. The results obtained at 7, 14 and 28 days were shown graphically. The various conclusions that can be drawn from this project work are given below:

1. Different mineral admixtures can be used as a partial replacement of cement in the concrete mix to give improved flexural strength.

2. Silica fume gives the highest values of flexural and compressive strength as compared to RHA and iron slag.

3. The highest value of flexural strength is obtained by $15 \%$ replacement of cement with silica fume.

4. The result obtained with the replacement of cement with iron slag also gives the highest value of flexural and compressive strength for 15 $\%$ replacement.

5. The test specimens created with RHA as replacement of cement have a lowest value of both compressive and flexural strengths.

6. The 28 days flexural strength for $5 \%$ replacement of cement with Silica fume, RHA and Iron slag increases by $17.21 \%, 16.28 \%$ and $0.1 \%$ respectively in comparison to concrete having no admixture.

7. For $10 \%$ replacement of cement with Silica fume, RHA and Iron slag the 28 days flexural strength increases by $24.19 \%, 1.4 \%$ and $20.7 \%$ respectively in comparison to concrete having no admixture.

8. For $15 \%$ replacement of cement with Silica fume and Iron slag the 28 days flexural strength increases by $30.93 \%$ and $21.86 \%$ respectively and it decreases for RHA.

9. The weight density of the test specimens created with RHA was the lowest and was much lower than the concrete without any mineral admixtures. Thus RHA can be used as a constituent in the formation of light weight concrete.

10. The samples created with RHA and Silica Fume as replacement of cement had much lesser weight density.

11. The flexural strength of concrete with RHA decreases with increasing the replacement of cement with RHA.

12. The compressive strength of test specimen with silica fume was much higher than the concrete mix design.
13. Iron slag can be suitably used as a replacement of cement as it is an abundantly available waste product and is also very cheap in comparison to silica fume and cement.

14. Steel slag and silica fume gives high early strength to the concrete as compared to RHA and the concrete without any admixture.

15. The 28 days compressive strength obtained with silica fume is much larger than the characteristic compressive strength of the concrete.

16. The compressive strength obtained with Iron slag and RHA is lower than that obtained for concrete without any replacement.

17. A very small percentage $(5 \%)$ of unprocessed RHA can be used as a constituent of concrete to obtain low cost concrete and unprocessed rice husk ash can be used in rural areas for making low cost houses.

18. The main reason for increase in strength is the filling of voids between the concrete particles by the admixtures.

The compressive strength of concrete containing RHA is always lower than that of concrete without any replacement of cement.

\section{REFERENCES}

[1] Gonen,T. and Yazicioglu,S. “ The influence of mineral admixtures on the short and long term performances of concrete" department of construction education, Firat University, Elazig 23119, Turkey.2009.

[2] M.J Shannag(2000),High Strength Concrete Containing Natural Pozzolanas and Silica Fume, Cem Conc Comp.22(6): 399-406

[3] H.A Toutanji, Z.,Bayasi "Effect of curing procedures on properties of silica fume concrete", Cement and Concrete Research, No. 4, 29(1999) 497-501.

[4] Sandor, P. "Portland Cement- Fly ash- Silica fume Systems in concrete "Department of Civil and Architectural Engineering, Drexel University, Philadelphia, Pennsylvania.

[5] Sabir B.B. High strength condensed silica fume concrete, Magazine of Concrete Research No. 172, 47(1995) 219-26.

[6] Khedr SA, Abou-zeid Mn. Characteristics of silica fume concrete. Journal of Materials in Civil Engineering ASCE, No. 3, 6(1994) 357-75. 
